\title{
The Preparation of Coating Material by Modified Asphalt Waterproof Roll Material
}

\author{
$\mathrm{Su} \mathrm{ZHAO}$ \\ School of material science and engineering \\ Shenyang architecture university \\ Shenyang, Liaoning \\ e-mail:zhaosu2005@126.com \\ Ruo-nan WANG \\ School of material science and engineering \\ Liaoning science and technology college \\ Benxi, Liaoning \\ e-mail:2515363294@qq.com
}

\begin{abstract}
In order to enlarge the utilization of the Buton rock asphalt, reduce the cost of polymer modified asphalt waterproofing roll materials, After mixing Buton rock asphalt into matrix asphalt, adding polymer SBS modifier, and prepare composite modified Buton rock asphalt, Then add the suitable amount of naphthenic oil, PP, talcum powder to prepare coating material by modified asphalt waterproof roll material. So, determine the experiment conditions of SBS and BRA composite modified asphalt, and the size of BRA should be selected within $0.075 \mathrm{~mm}$. The mixed BRA replacing part of the SBS modifier plays great role, not only reduces the cost of production, also improve the performance of the modified asphalt.
\end{abstract}

Keywords-modified asphalt; waterproof roll material; Buton rock asphalt; coating material

Waterproof materials of building industry have developed rapidly in our country, the structure of product also have very largely changes, the proportion of modified asphalt waterproofing materials in the waterproofing material market is bigger and bigger. However the high cost of polymer modified asphalt waterproofing materials affects its popularization and application[1-2], so the development of cost-effective of modified asphalt waterproofing materials becomes particularly important.

Natural asphalt has a wide distribution in the world, and belongs to the same nature material with the petroleum asphalt, and have similar chemical structure and properties. With the shortage of oil resources in today's, the use of natural asphalt replacing part of the matrix asphalt, not only reduces the cost of asphalt, also is more of great significance for the development of new energy, at the same time, the addition of natural asphalt can improve the matrix asphalt aging resistance properties[3]. Although the researches on the application of the natural asphalt at home and abroad are not uncommon, it is generally used in asphalt pavement engineering[4-6], and application scope is limited. Therefore, this research use Buton rock asphalt which is belongs to natural asphalt (BRA) to modify the matrix asphalt and then prepare waterproofing roll materials,

\author{
Da-ren GUAN* \\ School of material science and engineering Shenyang \\ architecture university \\ Shenyang, Liaoning \\ e-mail:375533139@qq.com
}

\author{
Guang-yi MA \\ School of material science and engineering \\ Shenyang architecture university \\ Shenyang, Liaoning \\ e-mail:962799702@qq.com
}

planing to expand its range of application.

Elastomer modified asphalt waterproof roll material is consisting of three parts which are coating materials, surface segregation materials and base material. While the coating material is made of asphalt, modifier and auxiliary solvent, filler,etc[7].After mixing Buton rock asphalt into matrix asphalt, get the Buton rock modified asphalt, then add polymer SBS(styrene-butadiene-styrene block copolymer) modifier, and according certain formula[8] to prepare waterproofing roll materials.

Compared with SBS modified asphalt, the mixed BRA replacing part of the SBS modifier plays a role, not only reduces the cost of production, and improve the heat resistance and segregation resistance of modified asphalt, also improve the performance of the modified asphalt. Due to the $70 \%$ composition of Buton rock is carbonate, so more than of carbonate rock, therefore, the mixed cloth, rock can replace some or all of filler like the talcum powder,etc.

\section{THE EXPERIMENT PART}

\section{A. Main Raw Material}

Maoming 90\# asphalt, Indonesia Buton rock asphalt; PP(polypropylene);naphthenic oil; talcum powder; SBS(styrene-butadiene-styrene block copolymer)is linear polymers.

\section{B. Experimental Method}

\section{1)The pretreatment of the BRA}

Crush the Buton rock asphalt, and get the Buton rock powder below 75um.

2)The preparation of coating material by modified asphalt waterproof roll material

Heat adequate amount of maoming 90\# matrix asphalt to $120-145^{\circ} \mathrm{C}$, add a certain amount of Buton rock asphalt, then mixing $0.5 \mathrm{~h}$ at a low-speed, making the Buton rock evenly disperse in the matrix asphalt, at last get the Buton rock modified asphalt. Then heating the Buton rock modified asphalt to $185-190^{\circ} \mathrm{C}$, add a certain amount of SBS and continue to mix 2h, making the SBS evenly 
dispersed in the modified asphalt, and, in turn, respectively add the suitable amount of naphthenic oil, PP, talcum powder in a certain order, mix 5h,finally get the elastomer modified asphalt waterproofing roll material[8].

\section{Performance Testing}

Do the performance test such as penetration, ductility, softening point, low temperature flexibility, elastic recovery, segregation with the relevant national standards.

\section{RESULT AND DISCUSSION}

A. The Influence of BRA Miscible with Asphalt at Different Time and Temperature
Respectively heat the matrix asphalt to $120^{\circ} \mathrm{C}, 125^{\circ} \mathrm{C}, 125^{\circ} \mathrm{C}, 135^{\circ} \mathrm{C}, 140^{\circ} \mathrm{C}, 145^{\circ} \mathrm{C}$ and maintain the temperature, then add $20 \%$ of the BRA, mix $0.5 \mathrm{~h}, 1 \mathrm{~h}, 1.5 \mathrm{~h}$ and $2 \mathrm{~h}$, the dissolving condition as shown in table 1 .

Can be seen from table 1 , when the temperature is $135^{\circ} \mathrm{C}$, the mixing time is $0.5 \mathrm{~h}, \mathrm{BRA}$ and matrix asphalt are completely dissolved, and the miscibility works best. So determine the preparation conditions of BRA modified asphalt: heat matrix asphalt to $135^{\circ} \mathrm{C}$, according a certain ratio to add $\mathrm{BRA}$, and mix $0.5 \mathrm{~h}$, lead BRA evenly distribute in the matrix asphalt.

Table 1. THE INFLUENCE OF BRA MISCIBLE WITH ASPHALT AT DIFFERENT TIME AND TEMPERATURE

\begin{tabular}{|c|c|c|c|c|c|c|}
\hline $\mathrm{Te}$ & 120 & 125 & 130 & 135 & 140 & 145 \\
\hline 0.5 & Not dissolved & $\begin{array}{l}\text { Not obviously } \\
\text { dissolved, } \\
\text { more particles }\end{array}$ & $\begin{array}{c}\text { mostly } \\
\text { dissolved, less } \\
\text { particles }\end{array}$ & $\begin{array}{l}\text { Completely } \\
\text { dissolved, } \\
\text { no particles }\end{array}$ & $\begin{array}{l}\text { Completely } \\
\text { dissolved, } \\
\text { no particles }\end{array}$ & heavier smoke \\
\hline 1 & Not dissolved & $\begin{array}{l}\text { Less dissolved, } \\
\text { more particles }\end{array}$ & $\begin{array}{l}\text { Completely } \\
\text { dissolved, } \\
\text { no particles }\end{array}$ & $\begin{array}{c}\text { Completely } \\
\text { dissolved, } \\
\text { no particles }\end{array}$ & heavier smoke & - \\
\hline 1.5 & $\begin{array}{l}\text { Less dissolved, } \\
\text { more particles }\end{array}$ & $\begin{array}{c}\text { Partly dissolved, } \\
\text { obviously } \\
\text { particles }\end{array}$ & heavier smoke & heavier smoke & - & - \\
\hline 2 & $\begin{array}{l}\text { Less dissolved, } \\
\text { more particles }\end{array}$ & $\begin{array}{c}\text { mostly } \\
\text { dissolved, less } \\
\text { particles }\end{array}$ & heavier smoke & heavier smoke & - & - \\
\hline
\end{tabular}

B. The Influence of SBS Miscible with Asphalt at Different Time and Temperature

Miscibility temperature of SBS is higher than that of BRA miscible temperature, so when mix the SBS with modified BRA, the need to raise the temperature. At the $300 \mathrm{r} / \mathrm{min}$ of mixing speed, add $12 \%$ of SBS into the matrix asphalt, the dissolving condition as shown in table 2 .

According the experiment phenomenon to analyze: when the temperature is below $180^{\circ} \mathrm{C}$, although the SBS has partly dissolved, the miscibility effect is not obvious. With the increase of mixing time at $180^{\circ} \mathrm{C}$, SBS has been dissolved, but long time mixing also increase the energy consumption, Due to the volatilization of light component, miscibility time can not be too long. When heating to $190^{\circ} \mathrm{C}$, the speed of SBS dissolution ability up, mixing for $1 \mathrm{~h}$, most of the SBS has been dissolved, and the mixture only have less amount of small particles, and a reasonable amount of smoke; When mixing to $2 \mathrm{~h}$, mixture has no particles, and the SBS has been completely mixed with asphalt, then continue to mix, the amount of smoke is gradually increasing, mixing also become increasingly difficult. this is because that with the increase of mixing time, light component that can dissolve the SBS begin to evaporate, The SBS begins to gather, cross-linking, plastic modification, resulting in deterioration of mixture system. When the temperature up to $200^{\circ} \mathrm{C}$, SBS quickly begins to cross-linking, plastic modification, and at that time it is difficult to control the whole process. The temperature of $S$ $\mathrm{BS}$ and asphalt mixture must be strictly within the range of $185-190^{\circ} \mathrm{C}$, and maintain the mixing time at $2 \mathrm{~h}$.

So the test steps are determined: heat matrix asphalt to $135^{\circ} \mathrm{C}$, reference relevant ratio to add the BRA, mix $0.5 \mathrm{~h}$, 
making BRA uniformly distributed within the matrix asphalt, and then heat to $185^{\circ} \mathrm{C}$, mix with a certain ratio of
SBS, mixing 2h, SBS uniformly distributed in modified asphalt[9-11].

Table 2. THE INFLUENCE OF SBS MISCIBLE WITH ASPHALT AT DIFFERENT TIME AND TEMPERATURE

\begin{tabular}{|c|c|c|c|c|c|}
\hline - & $\begin{array}{r}\text { Temperature } \\
1{ }^{\circ} \mathrm{C}\end{array}$ & 170 & 180 & 190 & 200 \\
\hline & 1 & Not dissolved & $\begin{array}{l}\text { Not obviously } \\
\text { dissolved, } \\
\text { more particles }\end{array}$ & $\begin{array}{l}\text { Partly dissolved, } \\
\text { less particles }\end{array}$ & difficult to mix \\
\hline & 2 & Not dissolved & $\begin{array}{c}\text { Less dissolved, more } \\
\text { particles }\end{array}$ & $\begin{array}{l}\text { Completely } \\
\text { dissolved, } \\
\text { no particles }\end{array}$ & - \\
\hline & 3 & $\begin{array}{l}\text { Less dissolved, } \\
\text { more particles }\end{array}$ & $\begin{array}{c}\text { Partly dissolved, } \\
\text { obviously } \\
\text { particles }\end{array}$ & $\begin{array}{l}\text { heavier smoke, } \\
\text { bigger viscosity }\end{array}$ & - \\
\hline & 4 & $\begin{array}{l}\text { Less dissolved, } \\
\text { more particles }\end{array}$ & $\begin{array}{l}\text { Partly dissolved, } \\
\text { less particles }\end{array}$ & unable to mix & - \\
\hline
\end{tabular}

C. The Influence of Particle Size on BRA Modified Asphalt

In order to study the effects the particle size of BRA on the properties of the modified asphalt, According to test steps 1.2, take different particle sizes of BRA separately to mix with the matrix asphalt and prepare BRA modified asphalt, the content of BRA is $20 \%$, then respectively determine the penetration and ductility, the results are shown in table 3 and table 4 .

Table 3. INFLUENCE OF PARTICLE SIZE ON THE PENETRATION OF BRA ASPHALT

\begin{tabular}{cccccc}
\hline & times & & & & \\
particle size/mm & 1 & 2 & 3 & 4 & 5 \\
\hline 2.36 & 70 & 67 & 70 & 75 & 74 \\
1.18 & 73 & 72 & 74 & 71 & 69 \\
0.60 & 75 & 73 & 74 & 72 & 74 \\
0.30 & 73 & 74 & 75 & 73 & 74 \\
0.15 & 74 & 74 & 75 & 74 & 75 \\
0.075 & 75 & 75 & 75 & 74 & 75 \\
\hline
\end{tabular}

Note: Test condition is $25^{\circ} \mathrm{C}, 100 \mathrm{~g}, 5 \mathrm{~s}$, unit is $0.1 \mathrm{~mm}$.

Shown in table 3, if joining the equal amount of BRA (20\%), The smaller the particle size, the smaller the deviation of the test results.in turn the greater the particle size, the greater the deviation and test results, the greater the deflection, and The lower the reproducibility. The reason may be that the BRA contains a lot of mineral particles. In the penetration tests, when mineral particles of asphalt is bigger than the pinpoint, pinpoint can tip into the mineral grains and make penetration small. On the opposite, it has a trend to become larger. The penetration of mineral without discipline changes is because of the dispersion of the particle distribution. When the size of particles is in the case of $0.075 \mathrm{~mm}$ diameter, it is smaller than the diameter of the tip in penetration test, so the mineral materials in BRA can evenly dispersed in the BRA modified asphalt, and play a good modification effect. Filler and asphalt have smaller relatively difference in density, and filler is not easy to occur precipitation in the asphalt BRA. The combination of stand or fall between filler and asphalt is related to the size of the adhesive surface, the larger the surface area, the better the the combination with the asphalt, and the greater the stability of the system.

\begin{tabular}{cccccc}
$\begin{array}{c}\text { Table 4. THE INFLUENCE OF BRA PARTICLE SIZE ON THE } \\
\text { EXTENSION DEGREE OF MODIFIED ASPHALT }\end{array}$ \\
\hline times & 1 & 2 & 3 & 4 & 5 \\
\hline 2.36 & 57.2 & 54.3 & 56.7 & 53.4 & 56.0 \\
1.18 & 58.0 & 56.4 & 58.6 & 58.9 & 56.3 \\
0.6 & 57.6 & 58.0 & 58.6 & 57.6 & 58.1 \\
0.3 & 57.8 & 58.8 & 58.6 & 62.8 & 57.1 \\
0.15 & 65.3 & 63.3 & 65.1 & 65.4 & 63.7 \\
0.075 & 67.7 & 68.2 & 68.4 & 68.2 & 67.0 \\
\hline
\end{tabular}

Note: Test condition is $15^{\circ} \mathrm{C}$, unit is $1 \mathrm{~cm}$.

As shown in table 4, When the size of particles is in the case of less than $0.6 \mathrm{~mm}$ diameter, with the reduction of grain size, the ductility of BRA modified asphalt has the tendency to become larger. This is due to that the size of BRA become smaller, making the BRA mixed with the matrix asphalt more evenly, the possibility of stress concentration appears become smaller, so it can avoid the premature fracture, make ductility values gradually tend to be more accurate. When the BRA size under the condition 
of only $0.075 \mathrm{~mm}$, ductility value fixed in $68 \mathrm{~cm}$, and generally there is no change. this is also why use $0.075 \mathrm{~mm}$ size of particle to prepare BRA modified asphalt, and discuss the modification effect.

\section{The Influence of SBS Content on Modified Asphalt Softening Point}

The influence of SBS and BRA content on modified asphalt softening point is shown in figure 1 .

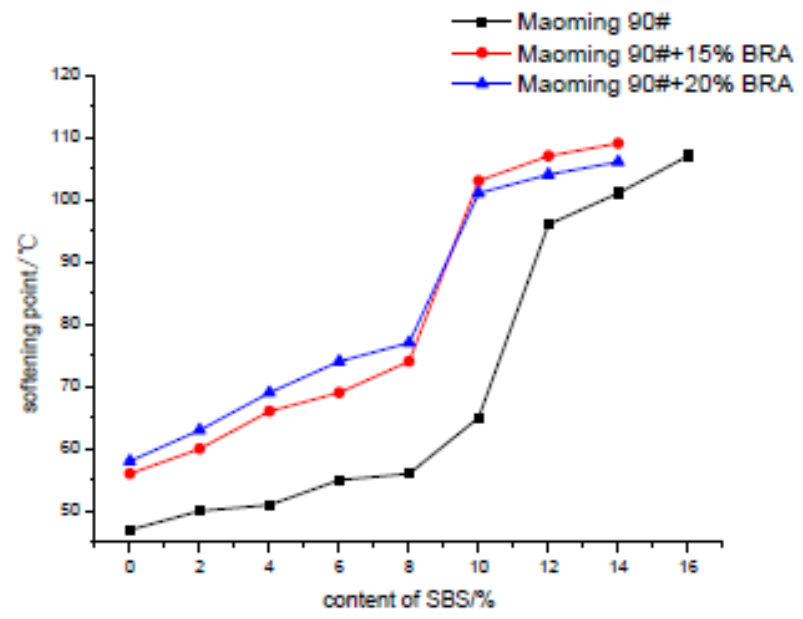

Figure 1. The influence of SBS content on modified asphalt softening point

The results showed: Under the condition of the SBS modified, softening point improved with SBS content increased. The dose is less than $8 \%$, the increasing speed is relatively moderate; while the dose is more than $12 \%$,rising speed of softening point is relatively fast, and has a mutation point between $10-12 \%$. Under the modification with SBS and BRA, the whole changing rule is the same. The abrupt changing point of the softening point jump in advance by $8-10 \%$.When the dose of SBS is more than $10 \%$, the rising speed of softening point modified by $20 \%$ BRA asphalt is lower than its content is $15 \%$,the reason is that the large number of minerals of BRA effect the blending of SBS and modified asphalt.

\section{E. Talcum Powder and BRA Modified Asphalt}

After heating matrix asphalt to $135^{\circ} \mathrm{C}$,respectively adding $5 \%, 10 \%, 15 \%, 20 \%, 25 \%$ and $30 \%$ content of BRA and $11 \%, 20 \%, 28 \%, 34 \%, 39 \%$ and $44 \%$ content of talcum powder into matrix asphalt, mixing $0.5 \mathrm{~h}$,At last, the modified asphalt can be obtained, then test the penetration degree. As shown in the figure 2.

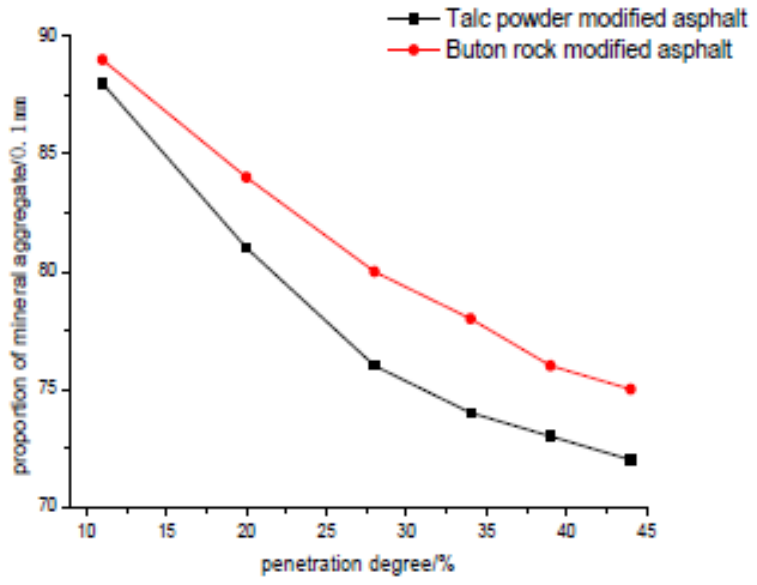

Figure 2. Talcum powder and BRA modified asphalt penetration

The results of modified asphalt penetration showed: Increasing content of talcum powder and BRA, modified asphalt penetration have a tendency to decline. In other words, Whether mix with the BRA or talcum powder, asphalt will become harder and its resistance to deformation is also enhanced; The decline of modified asphalt penetration is roughly the same after mixing talcum powder and BRA. So, if it is used for packing, BRA can replace some or all of filler like the talcum powder,etc.

\section{CONCLUSION}

Determine the preparation conditions of BRA modified asphalt: heat matrix asphalt to $135^{\circ} \mathrm{C}$,according a certain ratio to add BRA, and mix $0.5 \mathrm{~h}$, lead BRA evenly distribute in the matrix asphalt.

Determine the experiment conditions of SBS and BRA composite modified asphalt: heat matrix asphalt to $135^{\circ} \mathrm{C}$, add a relevant ratio of BRA, mix 0.5h,making BRA uniformly distributed within the matrix asphalt, and then heat to $185^{\circ} \mathrm{C}$, mix with a certain ratio of SBS, mixing 2h,SBS uniformly distributed in modified asphalt.

The size of BRA should be selected within $0.075 \mathrm{~mm}$.

The results of talcum powder and BRA modified asphalt penetration showed: Whether mix with the BRA or talcum powder, asphalt will become harder and its resistance to deformation is also enhanced; The decline of modified asphalt penetration is roughly the same after mixing talcum powder and BRA. So, if it is used for packing, BRA can replace some or all of talcum powder.

\section{REFERENCES}

[1] Hai Wang . The studying of performance and preparation of waterproof roll material by using composite rubber powder modified asphalt [D]. Wuhan University of Technology, 2010.

[2] Jun-wei li. Introduction of Polymer modified asphalt waterproofing materials[J]. Petroleum asphalt,2005,02:54-57.

[3] Liang Fan, Xiaojin Song, Yuzhen Zhang.Experimental research on road performance of natural asphalt modified asphalt mixtures. Advanced Materials Research, 2011,(287-290): 762-766.

[4] Liang fan,Liping Lin, Quanjun Shen, Yanyan Zhang. Experimental study and process optimization of natural rock modified asphalt[J]. China East highway, 2010,01:73-76. 
[5] Xudong Cha, lian Tong. Studying the properties of Indonesia Buton rock modified asphalt [J]. Changsha Jiaotong Journal University,2007,04:28-32. .

[6] Wentong Huang, Guoyuan Xu. Anti-rutting performance analysis of asphalt mixture with different natural asphalt Applied Mechanics and Materials,2014,529:256-259.

[7] Jun-wei li. Introduction of Polymer modified asphalt waterproofing materials[J]. Petroleum asphalt,2005,02:54-57.

[8] Jianguo Yu, Baozhu Ning, Zhimin Li, Yongning fan. SBS modified asphalt high self adhered waterproofing membrane and its production technology[P]. Inner Mongolia: CN16214502005-06-01.
[9] Qui Hu. Microstructure Quantitative technology and application of SBS modified asphalt [D]. Chang'an University, 2013.

[10] Ping Li, Lining Liu, Zhu Sun. Research on the storage stability test method of SBS modified asphalt. 2010 International Conference on Intelligent Computation Technology and Automation, 2010,03:178-181.

[11] Daliang Liu, Yunyong Huang, Jianlong Zheng et al. Study of mechanism of flame-retardant SBS-modified Asphalt[J]. International Journal of Pavement Research and Technology,2009,02(4):162-165. 